\title{
Exploring Managerial Perspectives of Using Building Management System through TAM: An Empirical Study of Commercial Sector of Pakistan
}

\author{
Ahsen Maqsoom*, Jameel Ur Rehman², Muhammad Umer, Muhammad Jamaluddin Thaheem, \\ Majid Jamal Khan ${ }^{3}$, Adnan Nawaz', Muhammad Najam ${ }^{5}$ Tahira Nazir ${ }^{3}$ \\ 1 Department of Civil Engineering, COMSATS University Islamabad Wah Campus, Quaid Avenue, Wah Cantt 47040, Pakistan \\ 2 Department of Management Science, Centre for Advanced Studies in Engineering (CASE), Islamabad 44000, Pakistan \\ ${ }^{3}$ Department of Management Science, COMSATS University Islamabad Wah Campus, Quaid Avenue, Wah Cantt 47040, Pakistan \\ ${ }^{4}$ Department of Construction Engineering and Management, National University of Science and Technology, Islamabad 44000, \\ Pakistan \\ ${ }^{5}$ Department of Computer Science, COMSATS University Islamabad Wah Campus, Quaid Avenue, Wah Cantt 47040, Pakistan \\ * Corresponding author, e-mail: ahsen.maqsoom@ciitwah.edu.pk
}

Received: 21 November 2019, Accepted: 15 April 2020, Published online: 12 May 2020

\begin{abstract}
A cursory review of the Building Management System (BMS) which optimizes building performance as a move towards smart cities has been presented in the present study. The extant study is an effort to distinguish and analyze the circumstances as if the underdeveloped economies are less likely to be benefitted by the contemporary trends of BMS as compare to the developed countries. Moreover, the current study identifies the factors which may cause to render the managerial acceptance for using BMS through the Technology Acceptance Model (TAM). TAM was used to measure four behaviors (latent factors) namely subjective norms, organization support, compatibility, and technology complexity. The data were statistically evaluated via multiple regression analysis using the Statistical Package for Social Sciences (SPSS). Results suggested that organization support and compatibility have a significant influence on managerial intentions to use BMS while subjective norms, technology complexity have no significant influence. The findings of this study may serve as guidelines for improvement in the acceptance process and using building management systems in commercial sectors of developing countries.
\end{abstract}

Keywords

building management systems, technology acceptance model, energy conservation, building automation systems, smart buildings

\section{Introduction}

Different sectors of a country consume energy to carry out their desired activities for various purposes [1]. According to the International Energy Outlook Report 2017 [2], released by US Energy Information Administration, indicated the energy demands expected to rise over the next three decades in the countries outside the Organization for Economic Cooperation and Development (OECD), particularly in Asia. Non-OECD Asia, including China and India, account for more than half of the world's total increase in energy consumption over the period spanned from 2015 to 2040. Many Asian countries have adopted or announced newer policies for implementing programs regarding energy conservation [3]. In these programs, various points focus on energy management in large buildings
[2]. The energy in any building is mainly used for lighting, equipment and for HVAC (cooling and heating) systems. Making those buildings more efficient may help owners to save their energy consumption and their expenses. The conception referring to the shift of the globe towards smart cities conferred to be the initial cells among others in entire cities [4]. Smart buildings make smart cities and hence help in making sustainable urban environment and in managing important resources [5]. The main intention of the management of any organization is to focus its activities in the line of reducing operating costs by introducing energy reduction practices. The operational phase of a commercial building is significantly longer than the design and construction phase of a project. The operational 
cost of a building is about 60 to 85 percent of the total lifecycle cost, whereas the design and construction are about five to ten percent $[4,6]$. Acquisition, renewal, and disposal costs are between five and 35 percent of the total life cycle cost [6].

For converting the buildings into smart and intelligent disposition, Building Management Systems (BMS) may be utilized for saving their energy $[3,7]$. BMS are generally installed in various facilities for the conservation of energy and it has been shown in studies that implementation of these systems may help to reduce their consumption of energies significantly when compared to normal or conventional ways of doing energy reduction without using BMS $[8,9]$.

In developing economies, few organizations are using BMS so far and this behavior indicates that there might be issues in not utilizing and accepting this technology for energy conservation. Technology Acceptance Model (TAM) has been used in various researches for exploring behavioral intentions of users and is well known, frequently applied and proven model in this regard for measuring the acceptance of new technologies in various sectors [10]. Previous studies have focused on industrial and domestic sectors, whereas, the extant study primarily focuses on the commercial sector to employ BMS for energy conservation and reduction in buildings' life cycle cost [11].

This article assesses the perspectives of managerial tiers in the commercial sector by measuring the level of influence of four latent factors of Technology Acceptance Model (TAM) that affect the behaviors in terms of accepted practices for using the Building Management System (BMS) in Pakistan. However, Pakistan has been reckoned as well defined since the last decade by foreign and local investors for the construction of high rise buildings containing international chains of hotels, malls, residential facilities, and corporate offices $[12,13]$. By the addition of each highrise building, energy demand increases in the commercial sector, which affects the total energy distribution and load management. Pakistan has been facing an acute shortage of power for more than a decade, therefore, energy demands for the commercial sector could be higher in the future than other sectors if the right approach would not be taken into account $[14,15]$. Hotel and lodging, health care, educational institutions, retail facilities, services, and office buildings are generally considered in this domain.

The next section offers a brief overview of the literature addressing the benefits of using BMS practices as well as previous use of TAM to measure the acceptance of new technologies. The third section encompasses the study's methodology and research framework and the fourth section provides our main findings and discussion. The article's final section offers conclusions and recommendations as well as limitations of the current study and future work.

\section{Literature review}

\subsection{Building Management System (BMS)}

The basic principle of BMS is to automate every system and to manage all the resources of the building [16]. This system can provide monitoring and control over building operational systems in order to get business and functioning efficiency. Buildings that have these systems installed consume less energy as compared to the structures without these systems [17], authors suggest that energy consumption decreases significantly in the buildings where automated hybrid systems have been installed. However, the current study compares both factors and draws the conclusion that intelligent buildings consume less energy when compared with traditional buildings (without automated systems). It also suggests that these buildings can reduce fuel consumption as well as $\mathrm{CO}_{2}$ emissions (green building concept). Borkowski and Pawloski [16] suggested in a study, which was carried out in Warsaw (Poland) for office and residential buildings, that by implementing building automation systems, it is possible to efficiently use energy and power and can have financial savings that lead to lower energy consumption and reduction in maintenance costs. Sita and Dobra [18] were in view that city resource management resource systems and the benefits including a reduction in resource consumption in order to save energy and resources for the future have characterized globally accepted phenomenon. If BMS installed structures can be integrated with city resource management systems, a huge amount of city resources could be saved in that pattern. The BMS application generally saves energy by $25 \%$ and manpower by $50 \%$; in a study of an airport, it was revealed that the load of the HVAC system took up about $40 \%$ of the total power of that facility and the load on the lighting system was about $35 \%$ [19]. It can be easily observed that both systems consume a considerable part of the energy of the airport terminal. Kolokotsa et al. [20] concluded that the fuzzy controller (for building automation) satisfies the indoor comfort requirements giving priority to passive techniques for heating, cooling, and lighting, thus minimizing the energy use by almost $38 \%$ without compromising indoor comfort. Macarulla et al. [21] determined that the results of the testing period revealed that the 
proposed control strategy reduced gas energy consumption by $19.69 \%$, without compromising the building users' thermal comfort. The energy demands in the developing countries in South East Asia, Middle East, South America and Africa will be increased by $3.2 \%$ in 2020 on average per annum. In other developed countries it will be $1.1 \%$ on average. In the categorization of overall energy consumption, buildings will be using 20 to $40 \%$ of produced energy in any given country with third in ranking after industry and transport [22]. Cingoski and Petrevska [23] suggest that hotels in Macedonia consume a substantial amount of energy for carrying its tourism operation. The tourists are fully aware of numerous environmental concerns the tourism development is facing, so they have shifted their accommodation preferences towards eco-friendly hotel establishments by preferring green products and showing a willingness to pay for "green" services. Consequently, the hotel industry is becoming increasingly environmentally responsible for taking care of energy efficiency.

It is obvious from various works of literature that by using a management system to control building operations, reduction in energy requirement has been observed and implies that there will be a definite saving in energy using BMS and where BMS is not yet installed, industry people are focusing on energy reduction seriously.

\subsection{Technology Acceptance Model (TAM)}

In 1975, Fishbein and Ajzen [24] proposed the Theory of Reasoned Action (TRA). This theory has become widely accepted in psychological researches. According to this theory, one's behavioral intention affects one's actual behavior.
It explained that one's behavioral intention for a specific behavior is affected by one's attitude and subjective norms. In terms of explanatory authority or theoretical basis, TRA has received a considerable degree of support and recognition. Keeping in view the aforementioned theory, Davis [10] have worked on TRA to explore the relationship among perception, factors of affections and technology usage, he used his results to construct the well-known Technology Acceptance Model (TAM) as shown in Fig. 1, which proposes that users' acceptance of a new system is affected by their attitude toward using the system. This model discusses the human behaviors regarding acceptance or adoption of new technologies.

The model has four major attributes of human perceptions or behaviors and these are highly dependent on each other to accept the new technology. This model is presented on the left side for placing appropriate external factors that could be influential to both attributes i.e., perceived usefulness and perceived ease of use at required circumstances. TAM basically defines the users' perspectives of adopting new methods or technologies with the help of perceived ease of use (PEU), perceived usefulness (PU) and attitude (A). These three basic behaviors determine the human perception of adoption. After the publication of Davis' study, many researchers used this model for investigation of user's perspectives towards acceptance of newer technologies and found this model valid for results [25].

Dulcic et al. [26] found in Croatia and suggested that perceived usefulness and perceived ease of use are important factors for using Decision Support Systems (DSS) in the management decision process. Holden and Karsh [27]

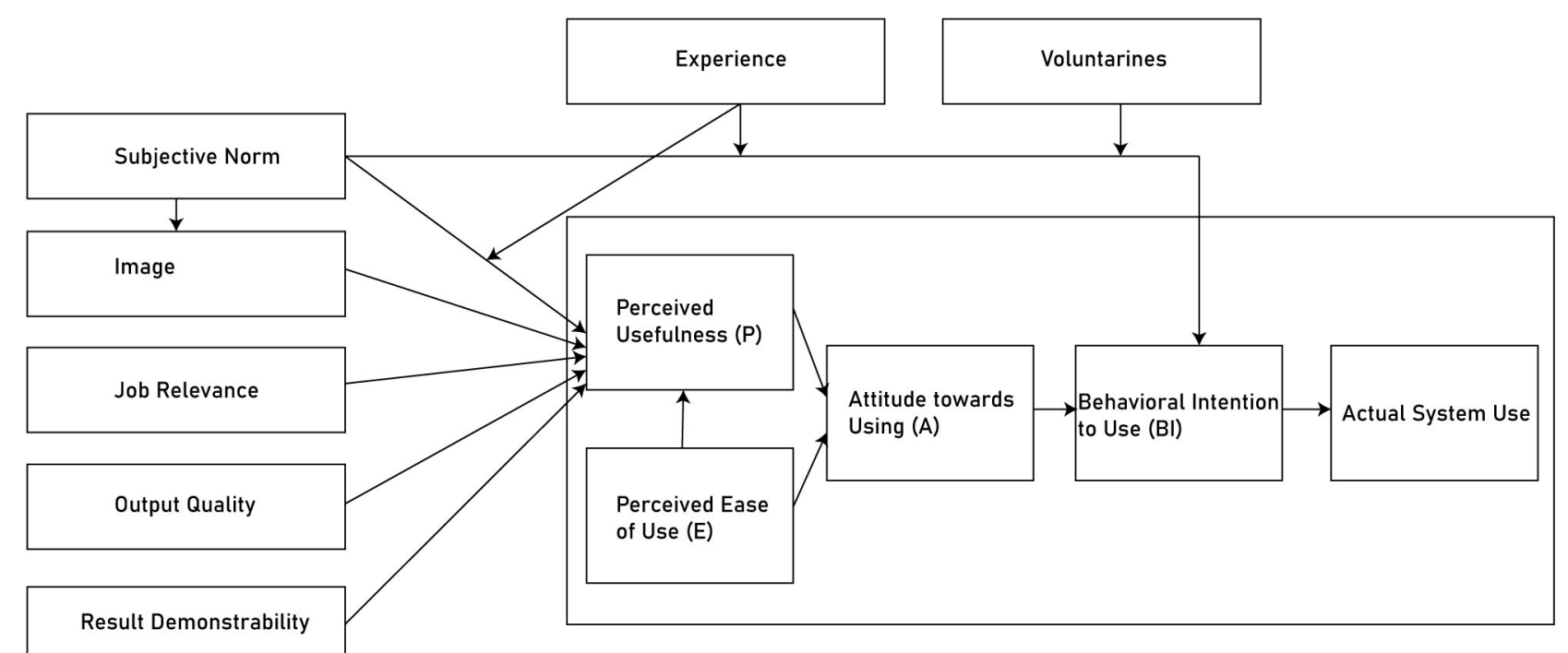

Fig. 1 Technology Acceptance Model [14] 
concluded in their research that Technology Acceptance Model (TAM) helps to find out the future of health IT, they suggested with appropriate factors, TAM could be used in the future to have newer technologies in the health sector. Özbek et al. [28] used TAM to assess the accepted behaviors in university students in their personality traits by using smartphones. Belanche et al. [29] clinched their study in Spain which tested the results of TAM with the external factors of trust and personal values (time consciousness and environmental concern) for e-government services adoption. In a Malaysian study, Ariff et al. [30] tested TAM with some external factors for acceptance of the internet banking system in undergrad students of marketing and was found valid. In Egypt, TAM was tested by Farahat [31] to assess learning through the online education system, university students have participated in this research and it was found that factors of TAM play important role in accepting the system. In Tunisia, Ibrahim [32] carried out research to find if the fantasy sports website will be accepted or not and the results indicated that the technology complexity factor led to higher perceived ease of use. Al Jardali et al. [33] conducted a study in Lebanon by using TAM for its model testing in order to investigate the intentions of using balanced scorecard and Information System in public sector organizations, this study has also used TAM for its model testing. Rajan and Baral [34] studied in India to find out the factors influencing the usage of ERP systems to end-users with some latent factors and suggested that organization support and compatibility have a positive influence on end-users. Chin and Lin [35] conducted research in Indonesia in order to investigate the perspectives of BMS users in manufacturing industries. They used TAM with external factors in their proposed model. Results suggested that only two external factors, which are compatibility and technological complexity, supported their model. The authors studied the workers' perspectives and suggested that managerial perspectives with relevant latent factors need to be studied for future researches.

Technology Acceptance Model (TAM) has been used widely around the world to determine the acceptable behaviors in different countries for the adoption of new technologies and amazingly found this model valid for almost all cases. Therefore, this study chose this model for finding appropriate external factors for using BMS technology by managers and to carry forward with the gap identified by Chin and Lin [35].

\subsection{Proposed external factors for TAM}

This study considers four elements as external latent factors for TAM in order to explore managerial perspectives of using BMS after reviewing a vast range of reputed journal papers. These elements include subjective norms (SN), organizational support (OS), compatibility (C) and technological complexity (TC).

\subsubsection{Subjective norms}

Subjective norms possess the concept of a substantial group or person's belief in order to support a specific code of conduct. Subjective norms are determined by the perceived social pressure from others for an individual to behave in a certain manner and their motivation to comply with those people's views [36].

\subsubsection{Organization Support}

In organizations that use technical systems, organizational support affects behavioral intention to use the system [24]. Organization support was categorized by Lee et al. [4] into a technology support and management support. Organization support (OS) is defined as the willingness of top management to provide the necessary resources and authority or power for project success [37].

\subsubsection{Compatibility}

Compatibility (C) can be explained as the degree to which an innovation is perceived as consistent with the existing values, past experiences, and needs of potential adopters [38].

\subsubsection{Technological complexity}

Aiman-Smith and Green [39] defined technological complexity as the extent to which new technology is more complicated for its user than the previous technology used for the same or similar work, and represents an increase in the number of things the user must do at once. It can be explained also as an individual perception of the difficulty understanding and using new technology [40-42].

These factors have been used in various pieces of literature in the past separately and have not been used simultaneously for TAM to analyze the adoption of BMS. This study uses these factors in an integrated form and selects the commercial sector of Pakistan as a case study. Some references for their uses in the past studies are mentioned in Table 1.

Venkatesh and Davis [36], have conducted research by using longitudinal studies. They used subjective norm to test its influence on user acceptance and found that this 
Table 1 External factors for TAM

\begin{tabular}{lc}
\hline Factors & Supported Literature \\
\hline $\begin{array}{l}\text { Subjective norms } \\
\text { (SN) }\end{array}$ & $\begin{array}{r}\text { Venkatesh and Davis [36], Chin and Lin [35], } \\
\text { Chou and Yutami [40], Son et al. [42] }\end{array}$ \\
$\begin{array}{l}\text { Organization } \\
\text { support (OS) }\end{array}$ & Son et al. [11], Rajan and Baral [34], [42], Amornkitpinyo \\
ampatibility (C) & and Wannapiroon [43] \\
Dechnology & Chin and Lin [35], Chou and Yutami [40], \\
complexity (TC) & Son et al. [42] \\
\hline
\end{tabular}

factor has a significant influence on PU and BI. Chin and Lin [35] have studied user's perspectives on manufacturing industries in Indonesia and tested the influence of subjective norms, compatibility and technology complexity on the Technology Acceptance Model. They found compatibility and technology complexity as critical factors for TAM. Chou and Yutami [40] have studied regarding smart meters' use in residential buildings in Indonesia. Their study found subjective norms and technology complexity as critical factors for user acceptance by using TAM. Son et al. [42] have conducted research on the acceptance of mobile computing devices in the construction industry in South Korea. They used subjective norms, organization support, and technology complexity to test their influence on the user's acceptance and found that all three factors have a significant influence on TAM. Amornkitpinyo and Wannapiroon [43] have studied the causal relationship model of the technology acceptance process for learning innovation in the modern era. They used organization support to test the model in their study. Chuo and Yutami [40] have conducted research on finding the effects of some factors on the usage intention of e-learning in the hospital. They used organizational support along with other factors and found it as a critical factor for TAM.

Based on the literature discussed above, the following hypotheses are proposed for testing the model:

H1: Subjective Norm (SN) has a significant influence on Behavioral Intention (BI) of managers to use BMS

$\mathrm{H} 2$ : Subjective Norm (SN) has a significant influence on Perceived Usefulness to Use (PU) of managers to use BMS

H3: Organizational Support (OS) has a significant influence on Perceived Usefulness (PU) of managers to use BMS

H4: Compatibility (C) has a significant influence on Perceived Usefulness (PU) of managers to use BMS

H5: Compatibility (C) has a significant influence on Perceived Ease of Use (PEU) to use BMS

H6: Technology Complexity (TC) has a significant influence on Perceived Expected Ease of Use (PEU) of managers to use BMS

H7: Perceived Ease of Use (PEU) has a significant influence on Perceived Usefulness (PU) of the managers to use BMS

H8: Perceived Usefulness (PU) has a significant influence on Attitude (A) of managers to use BMS

H9: Perceived Ease of Use (PEU) has a significant influence on Attitude (A) of managers to use BMS

H10: Attitude (A) has a significant influence on Behavioral Intention (BI) of managers to use BMS

Based on these hypotheses, behavior analysis is performed to explain the managerial acceptance for BMS. The proposed research model is presented in Fig. 2 indicating

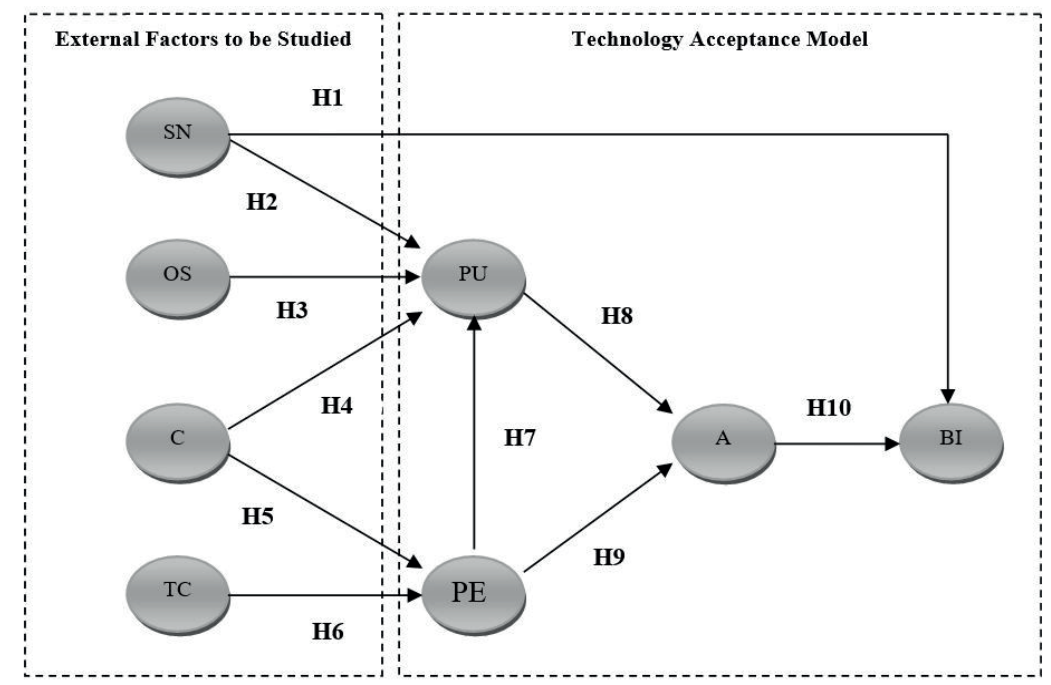

Fig. 2 Proposed research model 
all hypotheses and external factors for TAM. The suggested model is developed to elaborate on the influence of latent factors on the Technology Acceptance Model (TAM).

\section{Methodology}

\subsection{Procedure}

The objective of this study aims to explore and analyze the behaviors, which are essential for acceptance of a specific technology called Building Management System (BMS) generally used in large buildings for the conservation of energy. It was achieved by conducting a behavior analysis of functional managers, which are currently using this system in the commercial sector. This study adopted a quantitative approach, which included a review of the literature and an analysis of relevant publications for selecting appropriate latent factors for measuring behavior acceptance. Knowledge was also gained from relevant sources for smart buildings and energy-efficient concepts. The quantitative approach covered data analysis obtained from the survey questionnaires. For quantification, ten hypotheses have been developed for testing their influence. This research is a cross-sectional study i.e., taking information for one time only and preparing results from that information.

\subsection{Questionnaire development}

A survey questionnaire was developed to conduct the data collection part. The proposed model offers ten relationships for testing. These relationships were measured through questions that were prepared after extensive study of the literature and previous studies related to BMS and TAM. Ten relationships, as shown in Figc2, were considered as hypotheses and each hypothesis was measured through five items. In the questionnaire, research items are referred to as questions, which are fifty questions in total. The response for each question was gauged through a 5-point Likert scale where 1 represents strongly disagree, 2 represents disagree, 3 represents neutral, 4 represents agree and 5 represents strongly agree. The questionnaire consisted of three sections, first inquired about the respondents' general information, second questioned about company information and the third section included queries regarding the evaluation of the proposed research model. All participants in this study observed the same questionnaire. In the third part of the questionnaire survey, a set of questions were asked about the main factors of the model which are perceived ease of use (PEU), perceived usefulness (PU), attitude (A) and behavior intention (BI).
Another set of questions was asked about the external factors of the proposed model which are compatibility $(\mathrm{C})$, technology complexity (TC), subjective norms (SN) and organizational support (OS).

\subsection{Sample selection}

BMS technology is not being used extensively in Pakistan so far and there are very fewer companies and buildings that are using it, therefore the total population for this study was not much. Efforts were made to find out for all those companies that are using the BMS system and with the reference contacts, most of the buildings have been identified which are using this system in Punjab province of Pakistan. The questionnaire was also sent to Sindh province, but the response rate was very low because it was sent through e-mail service only. In Punjab province, the questionnaire was sent to approximately $90 \%$ of the subject population while the snowball sampling technique was used for Sindh province. Fifty-four (54) usable responses were received out of 110 questionnaires sent to the main cities of both provinces of Pakistan namely Islamabad, Rawalpindi, Lahore, Faisalabad, Multan, Hyderabad and Karachi on which analysis was carried out.

\subsection{Statistical analysis}

Statistical Package for Social Sciences (SPSS) was used to analyze the received data. Demographic information was collected and then after finding validity and reliability of questions, study results were generated by using correlation analysis followed by multiple regression analysis for hypotheses testing.

\section{Findings}

\subsection{Data Characteristics}

The data was collected from organizations that have been working in the commercial sector of Pakistan and are working in different services areas like service providers, healthcare, hospitality, and shopping malls. Section 1 and 2 of the questionnaires were related to demographic information of respondents and their firms. These sections were focused on gender, age, qualifications, professional experience, type of organization, a position attained and their BMS usage experience (Table 2).

The data in Table 2 showed the respondents' ages, qualifications, positions and experience in BMS are lying on the normal curve while professional experience and types of organization are not following it. Most of the respondents 
Table 2 Profile of surveyed respondents

\begin{tabular}{|c|c|c|}
\hline Characteristics & Frequency & Percentage \\
\hline \multicolumn{3}{|l|}{ Age (years) } \\
\hline Less than 25 & 6 & 11 \\
\hline 25 to 35 & 24 & 44 \\
\hline 36 to 45 & 15 & 28 \\
\hline Above 45 & 9 & 17 \\
\hline \multicolumn{3}{|l|}{ Qualifications } \\
\hline Diploma/Certificate & 15 & 28 \\
\hline Bachelors & 30 & 56 \\
\hline Masters & 9 & 16 \\
\hline \multicolumn{3}{|c|}{ Professional experience (in years) } \\
\hline 1 to 5 & 21 & 39 \\
\hline 6 to 10 & 9 & 17 \\
\hline Above 10 & 24 & 44 \\
\hline \multicolumn{3}{|l|}{ Type of organization } \\
\hline Service providers & 45 & 82 \\
\hline Hospitality & 3 & 6 \\
\hline Healthcare & 3 & 6 \\
\hline Malls & 3 & 6 \\
\hline \multicolumn{3}{|l|}{ Position attained } \\
\hline General manager & 18 & 33 \\
\hline Director & 21 & 39 \\
\hline Head of department & 15 & 28 \\
\hline \multicolumn{3}{|l|}{ BMS usage (years) } \\
\hline Less than 1 & 12 & 22 \\
\hline 1 to 5 & 30 & 56 \\
\hline More than 5 & 12 & 22 \\
\hline
\end{tabular}

are representatives of service providers because many organizations have outsourced the operation and maintenance of BMS technology to their service providers, whenever a problem is detected in the system, representatives of service providers are contacted for problem rectification. Few other organizations are related to hospitality, healthcare, and malls. The participants of this study have various BMS experiences and positions in their firms at mid and top-level namely General Managers, Directors and Heads of Department.

\subsection{Validity and reliability results}

Regarding the validity and reliability of results, the values of factor loadings have passed through the minimum threshold of 0.4 recommended by Straub et al. [44]. This indicates that the content of the questionnaire was good enough to explain the dimensionalities of SN, OS, C, TC, PEU, PU, $\mathrm{A}$ and BI. The values of Cronbach's alpha have been found to be above 0.7 as recommended by Chou and Yutami [40].

\subsection{Correlation coefficients}

Pearson correlation coefficients have been found for knowing the strength of the relationships between the variables of the proposed hypotheses. These coefficients indicate the association between the variables chosen in the hypotheses (Table 3).

Table 3 shows that the association between the variables used in the hypotheses is good enough except for the second hypothesis. Pearson correlation coefficients suggest that the relationship between $\mathrm{SN}$ and $\mathrm{PU}$ is weak with the insignificant level while the relationships of all other variables are strong at a good significance level. The results of correlation analysis allow the study to proceed for regression analysis to find the influence of variables in all hypotheses except the second.

\subsection{Multiple regression analysis}

Multiple regression has been used for making the regression equation to predict the values for dependent or response variables, which shows the unit changes in independent or explanatory variables. This tool also calculates the influence and causal effects of independent variables on dependent variables. The model of this study describes that there are four dependent variables with more than one independent variable therefore multiple regression has been used for testing of proposed hypotheses. According to the proposed model of the study, there are four dependent variables namely PU (perceived usefulness), PEU (perceived ease of use), A (attitude) and BI (behavior intention). These four dependent variables have more than one independent or explanatory variable. In the following, multiple regression analysis was performed for each above-mentioned dependent variable and the results are shown.

Table 3 Correlation coefficients of variables

\begin{tabular}{lcc}
\hline Hypothesis & Pearson's Correlation & Significance \\
\hline $\mathrm{SN} \Rightarrow \mathrm{BI}$ & 0.610 & 0.000 \\
$\mathrm{SN} \Rightarrow \mathrm{PU}$ & 0.073 & 0.599 \\
$\mathrm{OS} \Rightarrow \mathrm{PU}$ & 0.608 & 0.000 \\
$\mathrm{C} \Rightarrow \mathrm{PU}$ & 0.581 & 0.000 \\
$\mathrm{C} \Rightarrow \mathrm{PEU}$ & 0.780 & 0.000 \\
$\mathrm{TC} \Rightarrow \mathrm{PEU}$ & 0.569 & 0.000 \\
$\mathrm{PEU} \Rightarrow \mathrm{PU}$ & 0.701 & 0.000 \\
$\mathrm{PU} \Rightarrow \mathrm{A}$ & 0.790 & 0.000 \\
$\mathrm{PEU} \Rightarrow \mathrm{A}$ & 0.782 & 0.000 \\
$\mathrm{~A} \Rightarrow \mathrm{BI}$ & 0.964 & 0.000 \\
\hline
\end{tabular}




\subsection{Analysis of perceived usefulness (PU)}

The coefficient of determination tells us that the $\mathrm{R}$ square value is 0.559 with a standard error estimate of 0.395 (Table 4). This indicates that the collective effect from all independent variables on the dependent variable is approximately $56 \%$.

In Table 5, it is obvious that the dependent variable PU has four independent variables namely SN, OS, C and PEU. $\mathrm{SN}$ has a standardized beta value of 0.100 with the significance of 0.373 and it is known that the significance level should not be more than 0.05 for its acceptance. So, keeping that in view, SN has no significant effect on PU. OS has a standardized beta value of 0.496 with a significance of 0.012 which indicates that OS has a considerable effect on PU. C has a standardized beta value of -0.325 with the significance of 0.151 which is again not acceptable according to statistics. Finally, PEU has a standardized beta value of 0.626 with a significance of 0.000 and this is the most effective variable on PU.

\subsection{Analysis of perceived ease of use (PEU)}

The second dependent variable of the study is PEU, which has two independent variables $\mathrm{C}$ and TC. The value of $\mathrm{R}$ square is 0.616 with a standard error estimate of 0.407 (Table 6). The value of $\mathrm{R}$ square shows that the collected effect of both independent variables on the dependent variable is around $62 \%$.

$\mathrm{C}$ has a standardized beta value of 0.708 with a significance of 0.000 while TC has a standardized beta value of 0.113 with a significance of 0.325 (Table 7). In this analysis, it is clear, that $\mathrm{C}$ has a large effect on PEU with a greater beta value of 0.708 and its significance is high enough

Table 4 Coefficient of determination (PU)

\begin{tabular}{lcc}
\hline $\mathrm{R}$ & R Square & Adjusted R Square \\
\hline 0.748 & 0.559 & 0.523 \\
\hline
\end{tabular}

\begin{tabular}{lcc}
\multicolumn{3}{c}{ Table 5 Path coefficients } \\
\hline Model & St. $\beta$ Coefficients & Sig. \\
\hline SN & 0.100 & 0.373 \\
OS & 0.496 & 0.012 \\
C & -0.325 & 0.151 \\
PEU & 0.626 & 0.000 \\
\hline
\end{tabular}

Table 6 Coefficient of determination (PEU)

\begin{tabular}{lcc}
\hline $\mathrm{R}$ & $\mathrm{R}$ Square & Adjusted R Square \\
\hline 0.785 & 0.616 & 0.601 \\
\hline
\end{tabular}

for its acceptance. On the other hand, TC has a very low impact on PEU with a significant level higher than the acceptable range. Therefore, only $\mathrm{C}$ has to be considered for the final model.

\subsection{Analysis for Attitude (A)}

The third dependent variable of the study is A with two independent variables that are PU and PEU. Table 8 shows that the $\mathrm{R}$ square value is 0.755 with a standard estimate error estimate of 0.322 (Table 8). R square value suggests that both independent variables have collected an effect on the dependent variable equal to $76 \%$.

Table 9 suggests PU having a standardized beta value of 0.490 with a significance of 0.000 while PEU has a standardized beta value of 0.470 with the significance of 0.000 which indicates that both independent variables have considerable weights in a regression equation with very high significance level. So, both variables have been considered for the final model of the study.

\subsection{Analysis for Behavior Intention (BI)}

The last dependent variable is BI, which is the actual convincing behavior of the managers for using BMS technology. BI has two independent variables in the proposed model, which are SN and A. Referring to Table 10 the R square value is 0.931 with the minimum standard error estimate value of 0.141 which is very good in statistical analysis. This tells us that both independent variables have collected an effect on the dependent variable around $93 \%$.

\begin{tabular}{lcc}
\multicolumn{3}{c}{ Table 7 Path coefficients } \\
\hline Model & St. $\beta$ Coefficients & Sig. \\
\hline C & 0.708 & 0.000 \\
TC & 0.113 & 0.325 \\
\hline
\end{tabular}

Table 8 Coefficient of determination (A)

\begin{tabular}{lcc}
\hline $\mathrm{R}$ & $\mathrm{R}$ Square & Adjusted R Square \\
\hline 0.869 & 0.755 & 0.745 \\
\hline
\end{tabular}

Table 9 Path coefficients

\begin{tabular}{lcc}
\hline Model & St. $\beta$ Coefficients & Sig. \\
\hline PU & 0.490 & 0.000 \\
PEU & 0.470 & 0.000 \\
\hline
\end{tabular}

Table 10 Coefficient of determination (BI)

\begin{tabular}{lcc}
\hline $\mathrm{R}$ & R Square & Adjusted R Square \\
\hline 0.965 & 0.931 & 0.928 \\
\hline
\end{tabular}


Table 11 reflects SN having a standardized beta value of 0.045 with a significance of 0.331 . Effect value for SN has a very low impact on the dependent variable BI with an unacceptable significance level. A has a standardized beta value of 0.937 with the significance of 0.000 which is highly acceptable for the study. So, A has been considered for BI as an important behavior to accept new technology.

Finally, the study has some significant behaviors for suggesting the final model. Based on the statistical analysis, the following is the presentation of the hypotheses testing results (see Table 12).

Table 12 shows the summary of results for hypotheses testing. The test results show that 6 out of 10 hypotheses are supported. The hypotheses that are supported in the current research included H3, H5, H7, H8, H9, and H10. Whereas, this study results couldn't find any significant support for hypotheses H1, H2, H4 and H6 as their p-values were greater than 0.05 .

\section{Discussions}

This research identifies that subjective norms have no impact on behavior intention (H1 not supported) and perceived usefulness (H2 not supported). Organization support has a positive impact on perceived usefulness (H3 supported). Compatibility has a negative impact on perceived usefulness (H4 not supported) and has a positive impact on perceived ease of use (H5 supported). Technology complexity has no impact on perceived ease of use (H6 not supported). These are the external factors that have been tested in the Pakistani commercial sector. As it has been

Table 11 Path coefficients

\begin{tabular}{lcc}
\hline Model & St. $\beta$ Coefficients & Sig. \\
\hline SN & 0.045 & 0.331 \\
A & 0.937 & 0.000 \\
\hline
\end{tabular}

Table 12 Results of hypotheses testing

\begin{tabular}{lcccc}
\hline H\# & Hypotheses & $\beta$ & p-Value & Findings \\
\hline H1 & SN $\Rightarrow$ BI & 0.045 & 0.331 & Not Supported \\
H2 & SN $\Rightarrow$ PU & 0.100 & 0.373 & Not Supported \\
H3 & OS $\Rightarrow$ PU & 0.496 & 0.012 & Supported \\
H4 & C $\Rightarrow$ PU & 0.325 & 0.151 & Not Supported \\
H5 & C $\Rightarrow$ PEU & 0.708 & 0.000 & Supported \\
H6 & TC $\Rightarrow$ PEU & 0.113 & 0.325 & Not Supported \\
H7 & PEU $\Rightarrow$ PU & 0.626 & 0.000 & Supported \\
H8 & PU $\Rightarrow$ A & 0.490 & 0.000 & Supported \\
H9 & PEU $\Rightarrow$ A & 0.470 & 0.000 & Supported \\
H10 & A $\Rightarrow$ BI & 0.937 & 0.000 & Supported \\
\hline
\end{tabular}

observed that subjective norms have no influence on managerial behavioral intention and on perceived usefulness as in today's world businesses are getting more intelligent and people involved in any activity or business make their decisions on data rather than on others' opinions. Organization support has a significant influence on perceived usefulness because decisions of top management are always considered to be important for future growth, therefore if management supports for new technology then its adoption will be very easy and useful [45]. System compatibility does not have any influence on perceived usefulness as compatibility is not responsible for the importance of the system while it has a significant influence on perceived ease of use because if new technology has compatible properties with existing systems then it will create more interest and acceptability. If there is a genuine need for new technology, then its complexity does not matter. The results of this study are consistent with Maqsoom and Charoenngam [12] and Mohammad A. Hassanain et al. [46] for organization support and with Lowry [38] for compatibility, whereas they are partially consistent with Chin and Lin [35] and Chou and Yutami [40] due to difference in sample form.

Basic TAM was also tested and found that perceived ease of use has a positive impact on perceived usefulness (H7 supported). Perceived usefulness (H8 supported) and perceived ease of use have a positive impact on attitude (H9 supported). Attitude has a positive impact on behavior intention (H10 supported). All hypotheses in the original TAM are supported because this was developed after a rigorous study by Davis in 1989 [10]. The model explains the inter-related behavior of users for the adoption of new technologies. Any user may start using new technology after his or her positive intention towards that particular system. This positive intention (Behavior Intention) is triggered by the attitude (A) of that person for that technology or system. Now according to Davis, attitude may be influenced through two behaviors namely perceived usefulness and perceived ease of use. Perceived ease of use may trigger the perceived usefulness of a system. These behaviors are all linked with one another in a particular fashion and hence all hypotheses regarding these behaviors are supported in this study.

\section{Conclusions}

The aim of this research is to analyze the influence of external factors of the Technology Acceptance Model (TAM) on working managers for using Building Management System (BMS) in the commercial sector, as this will serve 
a guideline and the roadmap for energy conservation in buildings. Therefore, this research relates to the factors influencing managerial behaviors to accept this technology in their respective organizations. These behaviors are measured through a model proposed by Davis [10] called the Technology Acceptance Model (TAM). The first version of TAM is used for testing the proposed hypotheses with four external factors namely, subjective norms, organization support, compatibility, and technology complexity. However, it has been found that only two factors that are organization support and compatibility influence the user behaviors through perceived usefulness, perceived ease of use and attitude. Finally, the results of the study will be very useful for understanding the aspects of managerial intentions for using this state-of-the-art technology. Previous researchers have mostly conducted their studies in manufacturing sectors with a non-managerial population as their samples. However, this study focused on finding managerial perspective in the commercial sector because in any organization decision-makers are always the top management including CEOs, Directors, and Managers, therefore viewpoints of these positions matter a lot in accepting and using new technologies. The results of this study point out the thinking and perspective of managerial posts in the commercial sector for adopting the Building Management System.

\subsection{Implications}

The research assessing the managerial perception of managers regarding BMS usage in the commercial sector has been limited. Some studies focus only on the industrial sector to measure acceptance behavior for using BMS [35] or putting an accent only to the application of managerial perspectives of Hoteliers to use energy conservation techniques [23]. The current work doesn't restrict itself to such a focused approach in hotels or industry only, but it contributes to the previous literature by examining the whole commercial sector having different businesses and operations, which represents its novelty. The current research also has a practical contribution as it recommends a new approach in the commercial industry to decrease the operating costs and suggests that managers are in need of a better understanding of using BMS and the importance of energy efficiency. The study proposed that managers should induce more pro-environmental attitudes that are easily manageable if preparing various types of plans that may assist in initiating, monitoring and tracking the energy savings.
The key findings of this study, which have been generated from empirical pieces of evidence, will be useful for the policymakers and decision-makers in knowing about the needs of the managerial tiers working in the commercial sector. In addition, understanding of adoption factors will drive policymakers to formulate and develop strategies to increase the intention of the managerial tiers to adopt Building Management Systems to get its benefits.

The increased usage of BMS technology can bring many more benefits such as operational excellence, cost and time savings, increased efficiency, effectiveness and quality of public services. This point is significantly important in the commercial sector as the business activities are mostly run in this area. The government should implement energy-saving laws to make all sectors working in the same direction. Most of the owners and top management in developing countries, predominantly, the countries like Pakistan are unable to access these types of beneficial technologies because of inadequate resources and lack of awareness. The government should make the commercial sector aware of these services to boost the usage of those services and try to reduce the taxes on the purchasing of these expensive technologies. BMS service providers can use the results of this study for making their future strategies for sale and services and can focus on significant variables, which are organizational support and compatibility of the existing systems in buildings to make top management convinced and willing to use these valuable systems. However, it is anticipated that the findings of this study will serve as guidelines for BMS users and service providers to understand the required behaviors regarding managerial perspectives.

\subsection{Limitations and future directions}

This study has some limitations that also need to be addressed. The sample population is very small as this system is not being widely used in Pakistan. Responses from the Sindh province were very low due to the use of e-mail services only. This research took a large amount of time and faced data collection limitations; results could be better if this study was a longitudinal one. Future researchers may try to explore other relevant perspectives by integrating appropriate input variables or by applying TAM 2. This study focuses on managerial tiers however future studies may include owners, suppliers and other stakeholders for empirical investigations. 


\section{References}

[1] Jenkins, D. "Integrating building modelling with future energy systems", Building Services Engineering Research and Technology, 39(2), pp. 135-146, 2018. https://oi.org/10.1177/0143624418761478

[2] U.S. Energy Information Administration "International Energy Outlook 2017", Energy Information Administration, Washington, DC, USA, 2017. [online] Available at: https://www.eia.gov/outlooks/ieo/pdf/0484(2017).pdf

[3] Zhao, J., Xie, X., Liu, R., Sun, Y., Wu, M., Gu, J. "Water and energy saving potential by adopting pressure-reducing measures in highrise building: A case analysis", Building Services Engineering Research and Technology, 39(5), pp. 505-517, 2018. https://doi.org/10.1177/0143624417751056

[4] Le, M.-H., Ploix, S. "Robust anticipative energy management system: Application of a smart building platform", Building Services Engineering Research and Technology, 38(2), pp. 226-248, 2017. https://doi.org/10.1177/0143624416669832

[5] Allam, Z., Newman, P. "Redefining the Smart City: Culture, Metabolism and Governance", Smart Cities, 1(1), pp. 4-25, 2018. https://doi.org/10.3390/smartcities1010002

[6] Christian, J., Pandeya, A. "Cost Predictions of Facilities", Journal of Management in Engineering, 13(1), pp. 52-61, 1997. https://doi.org/10.1061/(ASCE)0742-597X(1997)13:1(52)

[7] Aslam, W., Soban, M., Akhtar, F., Zaffar, N. A. "Smart meters for industrial energy conservation and efficiency optimization in Pakistan: Scope, technology and applications", Renewable and Sustainable Energy Reviews, 44, pp. 933-943, 2015.

https://doi.org/10.1016/j.rser.2015.01.004

[8] Figueiredo, J., da Costa, J. S. "A SCADA system for energy management in intelligent buildings", Energy and Buildings, 49, pp. 85-98, 2012.

https://doi.org/10.1016/j.enbuild.2012.01.041

[9] Rocha, P., Siddiqui, A., Stadler, M. "Improving energy efficiency via smart building energy management systems: A comparison with policy measures", Energy and Buildings, 88, pp. 203-213, 2015. https://doi.org/10.1016/j.enbuild.2014.11.077

[10] Davis, F. D. "Perceived Usefulness, Perceived Ease of Use, and User Acceptance of Information Technology", MIS Quarterly, 13(3), pp. 319-340, 1989. https://doi.org/10.2307/249008

[11] Wong, L. T., Mui, K. W., Fong, N. K. "A humanized adaptive baseline information technology (HABIT) algorithm for a building management system", Building Services Engineering Research and Technology, 27(4), pp. 341-347, 2006. https://doi.org/10.1177/0143624406070662

[12] Maqsoom, A., Charoenngam, C. "Motives and competitive assets of Pakistani international construction contracting firms: Impact of size and international experience", Journal of Financial Management of Property and Construction, 19(2), pp. 138-151, 2014. https://doi.org/10.1108/JFMPC-09-2013-0037

[13] Maqsoom, A., Mughees, A., Zahoor, H., Nawaz, A., Mazher, K. M. "Extrinsic psychosocial stressors and workers' productivity: impact of employee age and industry experience", Applied Economics, 2019.

https://doi.org/10.1080/00036846.2019.1696936
[14] Akber, M. Z., Thaheem, M. J., Arshad, H. "Life cycle sustainability assessment of electricity generation in Pakistan: Policy regime for a sustainable energy mix", Energy Policy, 111, pp. 111-126, 2017. https://doi.org/10.1016/j.enpol.2017.09.022

[15] Ali, B., Zahoor, H., Nasir, A. R., Maqsoom, A., Khan, R. W. A., Mazher, K. M. "BIM-based claims management system: A centralized information repository for extension of time claims", Automation in Construction, 110, Article ID: 102937, 2020. https://doi.org/10.1016/j.autcon.2019.102937

[16] Borkowski, P., Pawlowski, M. "Home/Building Management Systems (HMS/BMS) to Protect Environment by Control Modern Lighting Installations", In: International Proceedings of Chemival, Biological and Environmental Engineering, 23, Singapore, 2011, pp. 141-145. [online] Available at: http://www.ipcbee.com/vol23/29CCEA2011-M10020.pdf

[17] Osma, G., Amado, L., Villamizar, R., Ordoñez, G. "Building Automation Systems as Tool to Improve the Resilience from Energy Behavior Approach", Procedia Engineering, 118, pp. 861-868, 2015. https://doi.org/10.1016/j.proeng.2015.08.524

[18] Sita, I.-V., Dobra, P. "KNX building automations interaction with city resources management system", Procedia Technology, 12, pp. 212-219, 2014. https://doi.org/10.1016/j.protcy.2013.12.477

[19] Manru, G., Wei, S., Lijun, X. "Engineering design of intelligent building management system (IBMS)", presented at the 2010 International Conference on Computer and Communication Technologies in Agriculture Engineering, Chengdu, China, June, 12-13, 2010.

[20] Kolokotsa, D., Niachou, K., Geros, V., Kalaitzakis, K., Stavrakakis, G. S., Santamouris, M. "Implementation of an integrated indoor environment and energy management system", Energy and Buildings, 37(1), pp. 93-99, 2005. https://doi.org/10.1016/j.enbuild.2004.05.008

[21] Macarulla, M., Casals, M., Forcada, N., Gangolells, M. "Implementation of predictive control in a commercial building energy management system using neural networks", Energy and Buildings, 151, pp. 511-519, 2017. https://doi.org/10.1016/j.enbuild.2017.06.027

[22] Pérez-Lombard, L., Ortiz, J., Pout, C. "A review on buildings energy consumption information", Energy and Buildings, 40(3), pp. 394 398, 2008.

https://doi.org/10.1016/j.enbuild.2007.03.007

[23] Cingoski, V., Petrevska, B. "Making hotels more energy efficient: the managerial perception", Economic Research-Ekonomska Istraživanja, 31(1), pp. 87-101, 2018. https://doi.org/10.1080/1331677X.2017.1421994

[24] Fishbein, M., Ajzen, I. "Belief, attitude, intention, and behavior: An introduction to theory and research", Addison-Wesley, Reading, MA, USA, 1977

[25] Wu, B., Chen, X. "Continuance intention to use MOOCs: Integrating the technology acceptance model (TAM) and task technology fit (TTF) model", Computers in Human Behavior, 67, pp. 221-232, 2017.

https://doi.org/10.1016/j.chb.2016.10.028 
[26] Dulcic, Z., Pavlic, D., Silic, I. "Evaluating the Intended use of Decision Support System (DSS) by Applying Technology Acceptance Model (TAM) in Business Organizations in Croatia", Procedia-Social and Behavioral Sciences, 58, pp. 1565-1575, 2012. https://doi.org/10.1016/j.sbspro.2012.09.1143

[27] Holden, R. J., Karsh, B.-T. "The technology Acceptance Model: Its past and its future in health care", Journal of Biomedical Informatics, 43(1), pp. 159-172, 2010. https://doi.org/10.1016/j.jbi.2009.07.002

[28] Özbek, V., Alnıaçık, Ü., Koc, F., Akkılıç, M. E., Kaş, E. "The Impact of Personality on Technology Acceptance: A Study on Smart Phone Users", Procedia - Social and Behavioral Sciences, 150, pp. 541551, 2014. https://doi.org/10.1016/j.sbspro.2014.09.073

[29] Belanche, D., Casaló, L. V., Flavián, C. "Integrating trust and personal values into the Technology Acceptance Model: The case of e-government services adoption", Cuadernos de Economía y Dirección de la Empresa, 15(4), pp. 192-204, 2012. https://doi.org/10.1016/j.cede.2012.04.004

[30] Ariff, M. S. M., Yeow, S. M., Zakuan, N., Jusoh, A., Bahari, A. Z. "The Effects of Computer Self-Efficacy and Technology Acceptance Model on Behavioral Intention in Internet Banking Systems", Procedia - Social and Behavioral Sciences, 57, pp. 448-452, 2012. https://doi.org/10.1016/j.sbspro.2012.09.1210

[31] Farahat, T. "Applying the Technology Acceptance Model to Online Learning in the Egyptian Universities", Procedia - Social and Behavioral Sciences, 64, pp. 95-104, 2012. https://doi.org/10.1016/j.sbspro.2012.11.012

[32] Ibrahim, H. "Technology Acceptance model: Extension to Sport Consumption", Procedia Engineering, 69, pp. 1534-1540, 2014. https://doi.org/10.1016/j.proeng.2014.03.152

[33] Al Jardali, H., Abdallah, F., Barbar, K. "Measuring Intentions among Employees toward the Use of a Balanced Scorecard and Information System: A Conceptual Approach Using the Theory of Planned Behavior and the Technology Acceptance Model", Procedia Economics and Finance, 26, pp. 1146-1151, 2015. https://doi.org/10.1016/S2212-5671(15)00944-2

[34] Rajan, C. A., Baral, R. "Adoption of ERP system: An empirical study of factors influencing the usage of ERP and its impact on end user", IIMB Management Review, 27(2), pp. 105-117, 2015. https://doi.org/10.1016/j.iimb.2015.04.008

[35] Chin, J., Lin, S.-C. "Investigating Users' Perspectives in Building Energy Management System with an Extension of Technology Acceptance Model: A Case Study in Indonesian Manufacturing Companies", Procedia Computer Science, 72, pp. 31-39, 2015. https://doi.org/10.1016/j.procs.2015.12.102
[36] Venkatesh, V., Davis, F. D. "A Theoretical Extension of the Technology Acceptance Model: Four Longitudinal Field Studies", Management Science, 46(2), pp. 186-204, 2000.

https://doi.org/10.1287/mnsc.46.2.186.11926

[37] Slevin, D. P., Pinto, J. K. "Balancing Strategy and Tactics in Project Implementation", Sloan Management Review, 29(1), pp. 33-41, 1987.

[38] Lowry, G. "Modelling user acceptance of building management systems", Automation in Construction, 11(6), pp. 695-705, 2002. https://doi.org/10.1016/S0926-5805(02)00010-9

[39] Aiman-Smith, L., Green, S. G. "Implementing New Manufacturing Technology: The Related Effects of Technology Characteristics and User Learning Activities", Academy of Management Journal, 45(2), pp. 421-430, 2002. https://doi.org/10.5465/3069356

[40] Chou, J.-S., Yutami, G. A. N. "Smart meter adoption and deployment strategy for residential buildings in Indonesia", Applied Energy, 128, pp. 336-349, 2014. https://doi.org/10.1016/j.apenergy.2014.04.083

[41] Kim, H.-J., Mannino, M., Nieschwietz, R. J. "Information technology acceptance in the internal audit profession: Impact of technology features and complexity", International Journal of Accounting Information Systems, 10(4), pp. 214-228, 2009. https://doi.org/10.1016/j.accinf.2009.09.001

[42] Son, H., Park, Y., Kim, C., Chou, J.-S. "Toward an understanding of construction professionals' acceptance of mobile computing devices in South Korea: An extension of the technology acceptance model", Automation in Construction, 28, pp. 82-90, 2012. https://doi.org/10.1016/j.autcon.2012.07.002

[43] Amornkitpinyo, T., Wannapiroon, P. "Causal Relationship Model of the Technology Acceptance Process of Learning Innovation in the 21ST Century for Graduate Students", Procedia - Social and Behavioral Sciences, 174, pp. 2090-2095, 2015. https://doi.org/10.1016/j.sbspro.2015.02.006

[44] Straub, D., Boudreau, M.-C., Gefen, D. "Validation Guidelines for IS Positivist Research", Communications of the Association for Information Systems, 13(1), pp. 380-427, 2004. https://doi.org/10.17705/1CAIS.01324

[45] Lee, S. M., Kim, I., Rhee, S., Trimi, S. "The role of exogenous factors in technology acceptance: The case of object-oriented technology", Information \& Management, 43(4), pp. 469-480, 2006. https://doi.org/10.1016/j.im.2005.11.004

[46] Hassanain, M. A., Bin-Mohanna, A., Al-Hammad, A.-M., SanniAnibire, M. O. "Challenges to the implementation of building management systems in Saudi Arabia", Built Environment Project and Asset Management, 7(2), pp. 130-142, 2017. https://doi.org/10.1108/BEPAM-05-2016-0022 